\title{
THE EFFECT OF A SPORTS PROGRAM ON REDUCING THE FAT COMPONENT OF OBESE WOMEN AGES (25-35) YEARS
}

\author{
Amanah Iyad Salman, Prof.Dr. Hamid Abdul Nabi Al-Fatlawi \\ University of Baghdad / College of Physical Education and Sports Sciences
}

DOI: $10.37648 /$ ijrssh.v10i02.034

Received: $30^{\text {th }}$ March, 2020; Accepted: $20^{\text {th }}$ April, 2020; Published: $13^{\text {th }}$ May, 2020

\begin{abstract}
The research included five sections, as the importance of the research lies in developing a training curriculum to know the extent of its effect in reducing the fatty component under the skin, as this method used specifically for the purpose of weight reduction for obese women ages (25-35) years, and the aim of the research was to prepare a sports program for obese women And identify the effect of the sports program on the physical variables of women, and the research assumed that there were statistically significant differences between the pre and post tests for some physical variables, and the sample included women who were randomly selected from women who wanted to lose weight in the Nutrition Research Institute and they number (18) Mother The researcher used the experimental method and conducted pre-test tests on 12/20/2019 and the training curriculum was applied three units per week, and dimensional tests were conducted on 20/2/2020 and then the results were statistically treated and the researcher concluded that the athletic program led to reducing the fat component of obese women in the measured areas and there is an effect Positive in body composition, and this was clearly demonstrated in body measurements, recommended to. Reduce the number of calories included in the diet from fat, and gradually increase the volume of training load through the number of iterations or groups in sports programs In the future.
\end{abstract}

\section{INTRODUCTION}

The natural body weight and the natural fats within it is an important subject for a person during the different stages of his life as well as one of the necessary indicators to follow the health, functional and psychological state. The increase in weight above the ideal proportions is a topic that cannot be ignored when talking about physical fitness.

Fat is the most component of the body that is subject to increase or decrease, and most of its increases or less in the body are caused by an imbalance between the number of calories entering the body through food and the number of calories consumed through vitality, life and athletic activity. In order to reduce weight when increasing the percentage of stored fat in the body, it is necessary to reduce the number of calories entering the body through dietary control and the use of an organized exercise program.

The importance of the research lies in the fact that women are an effective element in society and share tasks between them and men, which must receive adequate care and care, and that the lack of physical fitness and obesity is one of the situations that the Iraqi woman suffers from which causes her psychological frustration and lack of complacency, as well as the risks of suffering In many diseases, the best way to treat obesity is to use a healthy diet program and its effect on the fat component of obese women. 


\section{Research problem}

Through the field researcher's work for several years at the Al-Harithiya Center for Obesity and through her meeting with many workers in this field in sports clubs and fitness and weight reduction centers and health centers, I noticed that individuals who want to reduce their weight due to obesity are advised by doctors to follow a healthy diet that contains nutrients The basic and a sports program, as these individuals are likely to be exposed to some health risks, which lead to chronic diseases due to an unsupported food diet at the expense of the appropriate number of calories entering and leaving the body based on studied scientific principles and lack of exercise Exercise or exercise that is not scientifically directed to reduce weight by reducing stored fat and increasing fat-free weight (muscle weight), so the researcher decided to contribute to solving this problem by using a sports program that we can rely on to lose weight by reducing the fatty tissue of women Obese women within the age group (25-35) years, where the researcher hopes, through this program, to develop some solutions that help in upgrading the main pillar in society, but it is the woman.

\section{Research Objectives}

.Preparing a sports program for obese women aged (2535) years -

- Knowing the effect of the sports program on the physical variables of obese women, ages (25-35) years.
Research hypothesis

- There are statistically significant differences between the pre and post tests for some physical variables for obese women ages (25-35) years.

Research Areas

The Human Domain.: A sample of obese women between the ages of 25-35 years -

Spatial domain: Nutrition Research Institute / Baghdad / Al-Waziriya

Time domain: Duration 20/12/2019 to 20/22/2020.

\section{MATERIALS AND METHODS:}

\section{Research Methodology:}

The researcher used the experimental method, as it is the most suitable approach to solve the research problem, as the experimental approach is considered one of the most accurate and most efficient approaches in reaching reliable results.

\section{Search community and sample:}

The sample was chosen intentionally by women who attended the Nutrition Research Institute in Baghdad and aged (25-35) years, as they numbered 21 women and the researcher, three of them were excluded during the conduct of medical examinations, where they were found to have some health problems in the joints as they were Establish a mathematical program - fixed during (8) weeks, then take the mean and standard deviation for their ages, lengths, and weights as shown in the form:

Table (2)

The homogeneity of the subjects in the research sample shows the variables of age, height and weight

\begin{tabular}{|l|l|l|l|}
\hline skewness & standard deviation & Arithmetic mean & Variables \\
\hline $\mathbf{0 . 8 7 3}$ & $\mathbf{8 . 4 3 9 9 1}$ & $\mathbf{9 6 . 9 4 4 4}$ & the weight \\
\hline $\mathbf{0 . 4 2 7}$ & $\mathbf{3 . 5 0 7 2 3}$ & $\mathbf{2 9 . 2 2 2 2}$ & Age \\
\hline $\mathbf{0 . 6 3 2}$ & & & \\
\hline
\end{tabular}

Note that all torsional values were between $(+\ldots 3)$ and this indicates the homogeneity of the individuals of the search values within the natural curve.

Means of gathering information, tools and devices used in research:

:Devices and tools used in the research

.A medical scale (seca) for measuring weight and height -
A thickness caliper to measure the thickness of the skin fold -

.Digital camera for video filming -

.Personal computer (acer), bench, weights - 
(IJRSSH) 2020, Vol. No. 10, Issue No. II, Apr-Jun

Sources of information collection

.Arab and foreign sources -

.The Internet -

- Personal interviews.

Field research procedures:

Measurements used in the research

The researcher took some measurements for the research sample as follows:

overall length

- The unit of measurement used: the meter and its parts.

The device used: the SECA device to measure the length. -

Instructions: The laboratory stands just above the base of the device in the middle of it, so the body weight is distributed on both feet, the body is installed vertically and the heels are attached.

Recording: $1 / 100 \mathrm{~cm}$ is recorded.

Weight

Unit of measurement used: the kilogram and its parts. -

The device used: the SECA device for measuring weight. -

Instructions: The laboratory stands just above the base of the device in the middle of it, so the body weight is distributed on both feet, the body is installed vertically and the heels are attached.

Registration: to the nearest gram.

(Measuring the thickness of skin folds)calipers

The researcher used the Skinfold caliper device to measure the thickness of the folds of the skin, which is a device characterized by a high rate of firmness of the jaws and the measurement was taken from three areas in the body which are the area of the muscle of the three brachial heads (Triceps), the measurement of the back region (below the shoulder blade bone subscapular), and the area above the bone Iliac (Subrailiac)

Tools needed for the measurement: the skin callipers (grease) device, a tape measure and a ruler, included, a felt-tip pen.

Conditions to follow when measuring the thickness of the skin fold:

The thickness of the skin fold is measured in the anatomical areas referred to earlier, on the right side of
e-ISSN: 2249-4642, p-ISSN: 2454-4671

the body, and by qualified persons and that one person measure the entire sample of the research by means of a unified device, and the optimal way to measure the thickness of the skin fold is as follows:

- The anatomical region is first determined in the location at which the thickness of the skin fold is measured.

- The examiner, using one of his hands, places the index and thumb on the skin of the examiner, and the distance between them is about $(6-8) \mathrm{cm}$.

- The examiner then attracts the skin, by bringing the index finger and thumb close to each other, and then raises the skin folds away from the muscles within (2-3) $\mathrm{cm}$.

- With the other hand, the examiner places the instrument's jaws on the skin fold (away from the thumb and forefinger of a centimeter and one distance), then relaxes the jaws.

- The thickness is read directly from the device after about (2-3) seconds have passed from the stability of the indicator.

- Repeat the measurement over the same place two more times, and then take the average of the three readings.

- If the indicator continues to decline after several attempts, it is necessary to stop and then repeat the measurement again after several seconds.

- When completing the measurement and taking the reading, you should avoid pulling the jaws of the device directly from the skin.

- Rather, the jaws are compressed and then gently pushed away so as not to scratch the skin.

The researcher has made measurements for the following areas:

- Measuring the arm region (the fat layer above the three-brachial muscle) (Triceps):

Measurement was measured by holding the fold of the skin vertically from the middle of the upper arm region between the lateral (lateral) side of the acromial bulge of the bone of the shoulder blade and the elbow protrusion of the joint (elbow) on the three-headed humerus muscle, taking into account that the arm is relaxed and on the side of the body, as shown in the figure (1 and 2):-Measuring the subscapular region

Measured by holding the skin folds diagonally and at an angle of (45 degrees) and towards the right side of the female body and from the bottom end of the shoulder blade end. 

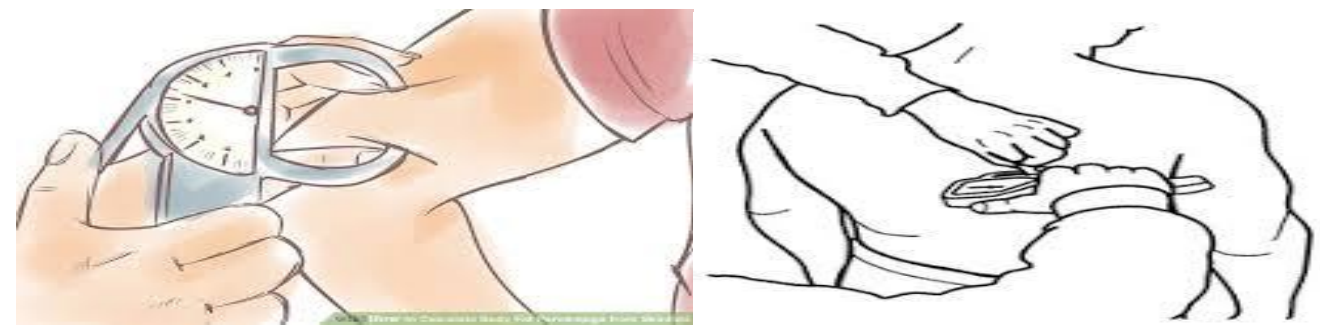

Figure (1 and 2)

Measurement of the thickness of folds of skin in the areas of the three-headed humerus and the subsurface bone

Suprailiac region

The measurement was carried out by holding the skin folds diagonally over the iliac bone area of the pelvis along the imaginary line from the mid-armpit region, and the researcher considered that the feet are close together, and the arms are to the side and outside slightly to facilitate the measurement process.
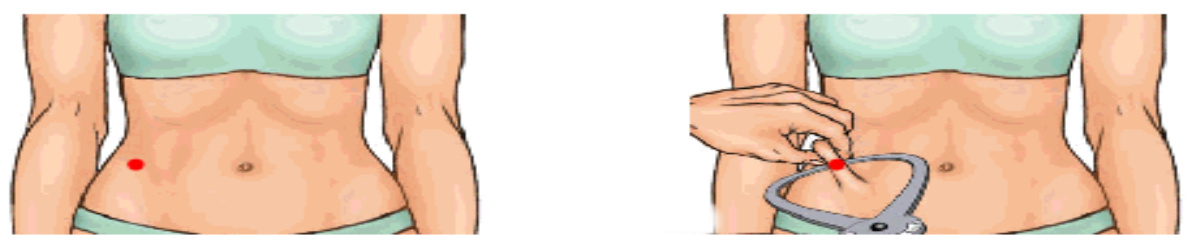

Figure (3) shows measuring the area above the iliac bone (Subrailiac)

\section{Exploration Experience}

The researcher conducted an exploratory experiment on (5) individuals from the research community, who were excluded when carrying out basic research procedures, and the experiment was done within one day, during which he conducted physical tests and functional measurements, as well as measurements of physical components, on (12/12/2019) and was The aim of the experiment is as follows:

.Verify the validity of the devices and tools used -

.Knowing the obstacles that appear and avoid errors and overlaps in work -

- Knowing the time required to perform measurements and tests for each individual.

- Knowing the mistakes that occur in this experiment to avoid them in the final experiment.

.Knowing the fitness of the closed hall for exercise -

\section{Main experience}

tests and tribal measurements
Tribal measurements were made before the start of implementing the mathematical program for lipid components, as they were done on (12/20/2019).

: Test and dimensional measurements

Dimensional measurements were performed after completing the mathematical program on Thursday $20 / 2020$, with the same sequence of tests and tribal Measurements.

\section{Statistical means}

The following statistical methods were used: Arithmetic mean (adjusted). -

.- standard deviation

Coefficient of torsion. -

- test (t).

\section{RESULT AND DISCUSSION:}

Display the results of the pre-test and post-test subjects. Presenting the results of the exams that are the subject of the research for the sample: 
Table (3)

Shows the arithmetic mean, standard deviations and torsional coefficient of pre- and post-exam tests

\begin{tabular}{|l|l|l|l|l|l|}
\hline skewness & standard deviation & Arithmetic mean & the test & $\begin{array}{l}\text { measruing } \\
\text { unit }\end{array}$ & the exams \\
\cline { 1 - 4 } 0.815 & 4.73286 & 26.0000 & Before & mlm & The muscle has three \\
brachial heads
\end{tabular}

To identify the differences in the pre and post tests of the research sample, the researcher intended to use the T test as shown in Table (4)

Table (4)

\begin{tabular}{|l|l|l|l|l|l|}
\hline $\begin{array}{l}\text { Significant } \\
\text { value }\end{array}$ & T value & F q & A-F & Q- F. & Variables \\
\hline $\mathbf{0 . 0 4 7}$ & $\mathbf{2 . 6 2 1}$ & $\mathbf{2 . 6 7 0 8 3}$ & $\mathbf{6 . 5 4 2 1 7}$ & $\mathbf{7 . 0 0 0 0 0}$ & $\begin{array}{l}\text { Muscleheaded } \\
\text { brachial }\end{array}$ \\
\hline $\mathbf{0 . 0 0 1}$ & $\mathbf{6 . 9 2 1}$ & $\mathbf{1 . 9 2 6 4 2}$ & $\mathbf{4 . 7 1 8 7 6}$ & $\mathbf{1 3 . 3 3 3 3 3}$ & $\begin{array}{l}\text { Muscles under the } \\
\text { scapula }\end{array}$ \\
\hline $\mathbf{0 . 0 1 5}$ & $\mathbf{3 . 6 3 0}$ & $\mathbf{3 . 2 6 0 0 3}$ & $\mathbf{7 . 9 8 5 4 0}$ & $\mathbf{1 1 . 8 3 3 3 3}$ & $\begin{array}{l}\text { Muscle above the } \\
\text { iliac bone }\end{array}$ \\
\hline
\end{tabular}

Shows the calculated value (T) and the value of the indication for the pre- and post-testing of the exams

Moral under significance level 0.05

The results of the tests showed that all measurements of skin folds in the research variables showed an improvement in the post test and the researcher instructed that to use various exercises and graduated training loads, as (Frederick) stated, "The benefits of these exercises are not limited to functional and physical aspects only, but exceed that to one of the important means In maintaining the integrity of the body and the consistency of body parts, especially if these exercises are performed continuously and correctly at regular times. Since the sample is of those with extra weights, the exercises used in the research worked to burn many fat under the skin in many areas, including the researched areas, and used these fats as an energy source, which reduced the level of their collection from under the skin. The practice of exercises worked to deliver a large amount of oxygen to the working muscles and therefore, despite the decrease in the lipid component, the working muscles remained retaining their strength and accordingly, the decrease was at the expense of the lipid component and not the muscular, where (Osama Kamel) mentioned a preferred return, "Physical activity guarantees weight loss from Accumulated fat and not muscle decay."

And as each of (Sari Ahmed) states that getting more muscles means burning more energy and that increasing her weight increases the metabolic rate. This explains the overall decrease in the thickness of the skin folds. Also, the regularity and continuity of training led to an increase in the destructive hormones that accompanied the exercises, which may have the effect of burning fats in the fatty tissues, which explain the fat loss that usually occurs by continuing training

Also, the training associated with the diversity of exercises indicates a significant change in the physical composition of the sample by increasing body weight 
without fat and decreasing body weight of fat, and this is what (Abu Al-Ella and Muhammad) indicated that long training causes an increase in body weight without fat Body fat decreases and the size of these changes depends largely on the type of exercise used.

\section{CONCLUSIONS:}

- The athletic program reduced the fat component of obese women in the measured areas.

.- There is a positive effect on the physical composition, and this was clearly demonstrated in the physical measurements
.- The exercises have worked to improve the health and fitness of the individual

\section{ENDORSEMENT:}

Reducing the number of calories included in the fat diet program. -

.- Increasing the training load gradually through the number of iterations or groups in future sports programs. Focus in the future on food-sports programs. -

\section{REFERENCES:}

- Qasim Hassan Hussein: The comprehensive mathematical and physical encyclopedia in sports and sports sciences, 1, Jordan, Dar Al Fikr for printing, publishing and distribution, 417, 1988.

- Saad Mohsen: Effect of training methods to develop the explosive force of both men and arms in the accuracy of remote correction by jumping high in handball, PhD thesis, Faculty of Physical Education, University of Baghdad, 1996.

- Ali Turki Musleh and Ahmad Yousef Al - Shamkhi: Design of the test accuracy of the correction, Qadissiya Journal of Physical Education Sciences, M1, p. 5, University of Qadisiyah, 2002.

-Hans-Gert Stein-Edgar Vederehoff: Handball, (translated) Kamal Abdel Hamid, Egypt: Dar Al Ma'arif, 1977.

- Fadhel Kurdi Shammari: Handball, University of Babylon, Library of the University of Babylon, 2005.

- Mohammed Tawfiq Al-Waili: Handball - Education - Training - Tactic, Kuwait, Kuwait Printing Company, 1989.

- Nuri Al-Shouk and Rafie Saleh: A guide to research writing in physical education, Baghdad, Higher Education Press, 2004.

- Diaa Al-Khayat and Noufal Mohammed Al-Hayali: handball, Mosul University, Dar al-Kuttab for printing and publishing, 2001.

- Ali Salloum: Tests, Measurement and Statistics in the Mathematical Field, Baghdad, Al-Taif Printing Press, 2004.

-- Kamal Darwish et al.: The Physiological Basis of Handball Training - Theories and Applications, The Book Center for Publishing, Cairo, 1998.

- Laith Ibrahim Jassim: Special Strength and its relationship with force and accuracy of correction during different levels of physical effort of youth handball players (ages 18-20), Journal of Physical Education Sciences, No. 3, Volume II, 2009.

- God God Basati: rules and foundations of sports training, Cairo, Dar Knowledge, 1998.

\section{$\operatorname{ANNEX}(1)$}

Physical exertion before skill performance

The player stands at the starting line and when the whistler moves and moves from the first person to the second person and then back to the first person and then to the third person and back to the first and so to the rest of the characters, and then jump on the barriers placed one foot alternating between the feet and then perform (10) batches and then running from point (A) to point (B) in the form of defensive follow-up back and forth and after performing the required skill test.

- Ahmed Nasr El-Din Sayed: Sports and Weight Loss, 1st edition: (Cairo, Dar Al-Fikr Al-Arabi, 1994).

- Abu Al-Ella Ahmed, Mohamed Sobhi: Physiology and Morphology of Mathematical Methods of Measurement and Evaluation (Cairo, Dar Al-Fikr Al-Arabi, 1997). 
- Ibrahim Abd Rabu Khalifa: The sport of walking is an entry point for achieving mental and physical health, 1st floor: (Cairo, Dar Al-Fikr Al-Arabi, 1998).

- Osama Kamel Ratib: The relationship of fat percentage and its variability on some physiological variables related to physical effort among children (PhD thesis, College of Physical Education - University of Baghdad 2000).

- Bahaa El-Din Ibrahim Salama: Mathematical health and physiological determinants of physical activity, 1st edition: (Cairo, Dar Al-Fikr Al-Arabi, 2002).

- Zakia Ahmed Fathi, Mahmoud Al-Najjar: Physiology of Sport, B edition: (Cairo, Al-Ghad Library and Press, 2001).

- Sari Ahmed Hamdan and Norma Abdul Razzaq: Physical Fitness and Health, 1st edition: (Amman, Wael Publishing House, 2001).

- Saleh Al-Areed and Turki Al-Khudair: Food and Sports, the Secret of Fitness, Successful Experiences in the Gulf Society, 1st Edition: Dar Tuwaiq for Publishing and Distribution, 2002).

- Abdul Rahman Musaiger and Muhammad Zain Ali: Food and Man - Principles of Food Science and Nutrition, 1 st edition: (Bahrain, Arab Nutrition Society Press, 1999).

- Mohamed Adel Roshdy: Nutrition in the sports field, 1st edition: (Alexandria, University Youth Foundation, 1999).

- Majed Abdel-Al: Obesity and Endocrinology, its causes and prevention, 1st edition: (Cairo, Al-Ahram Center for Translation and Publishing, 1995).

- Nawal Mudhar Ahmad Rafeeq: "The effect of reducing the lipid component on the fitness elements." An experimental study on women who had a higher fat percentage than their ideal limit, unpublished Master Thesis, University of Baghdad. 1994.

- Nasser Al-Daghri: Estimating the Boundaries of the Abdominal Country and its Link to the Traditional Indications of Obesity among Saudi Children and Adolescents, The Third Arab Conference on Obesity and Physical Activity: (Bahrain, 2010).

- Hazaa Bin Muhammad Hazaa: Physical effort physiology, theoretical foundations and the scientific procedures for physiological measurements, Part 1: (Saudi Arabia, King Saud University, scientific publishing and presses. 20090.

- Wadih Yassin and Muhammad Ali, Yassin Taha: "Physical preparation for women", b. I: (House of Books for Printing and Publishing, 1986).

- Yassin Taha Muhammad Ali (2000c): "The effect of a sports and nutritional program on some areas of fatty buildup in the human body," published research, Al-Rafidain Journal for Mathematical Sciences, Volume VI, Number Twenty-first.

- Frederick C. Hatield- Aerbic Fitness the beginners guide to imperial endurance- U.S.A. 1985.

- Vivian H. Heyward, Dale R. Wagner; Applied Body Composition Assessment, 2nd ed, USA, Human Kinetics, 2004.

Annex (1)

\begin{tabular}{|c|c|c|c|c|c|c|c|c|c|c|c|}
\hline \multirow{2}{*}{\multicolumn{2}{|c|}{ The final section }} & \multirow{2}{*}{\multicolumn{3}{|c|}{ The main section }} & \multicolumn{4}{|c|}{ Preparatory section } & \multirow{2}{*}{\multicolumn{3}{|c|}{ The first week }} \\
\hline & & & & & \multicolumn{2}{|c|}{ Special exercises } & \multicolumn{2}{|c|}{ General warm up } & & & \\
\hline Target & Time & Target & Distress & Time & Target & Time & Target & Time & \multirow[t]{2}{*}{$\begin{array}{l}\text { Total } \\
\text { time }\end{array}$} & \multirow{2}{*}{$\begin{array}{l}\text { day } \\
\text { and } \\
\text { date }\end{array}$} & \multirow{2}{*}{$\begin{array}{l}\text { Trainin } \\
\text { g unit } \\
\text { number }\end{array}$} \\
\hline $\begin{array}{l}\text { Calm } \\
\text { down } \\
\text { and } \\
\text { relax }\end{array}$ & $10 \mathrm{~m}$ & $\begin{array}{l}\text { The descent of } \\
\text { the lipid } \\
\text { component }\end{array}$ & $50 \%$ & $\begin{array}{l}15-17 \\
\mathrm{~m}\end{array}$ & $\begin{array}{l}\text { Exercises for } \\
\text { all parts of } \\
\text { the body }\end{array}$ & $5 \mathrm{~m}$ & $\begin{array}{l}\text { Warm } \\
\text { up }\end{array}$ & $10 \mathrm{~m}$ & & & \\
\hline
\end{tabular}




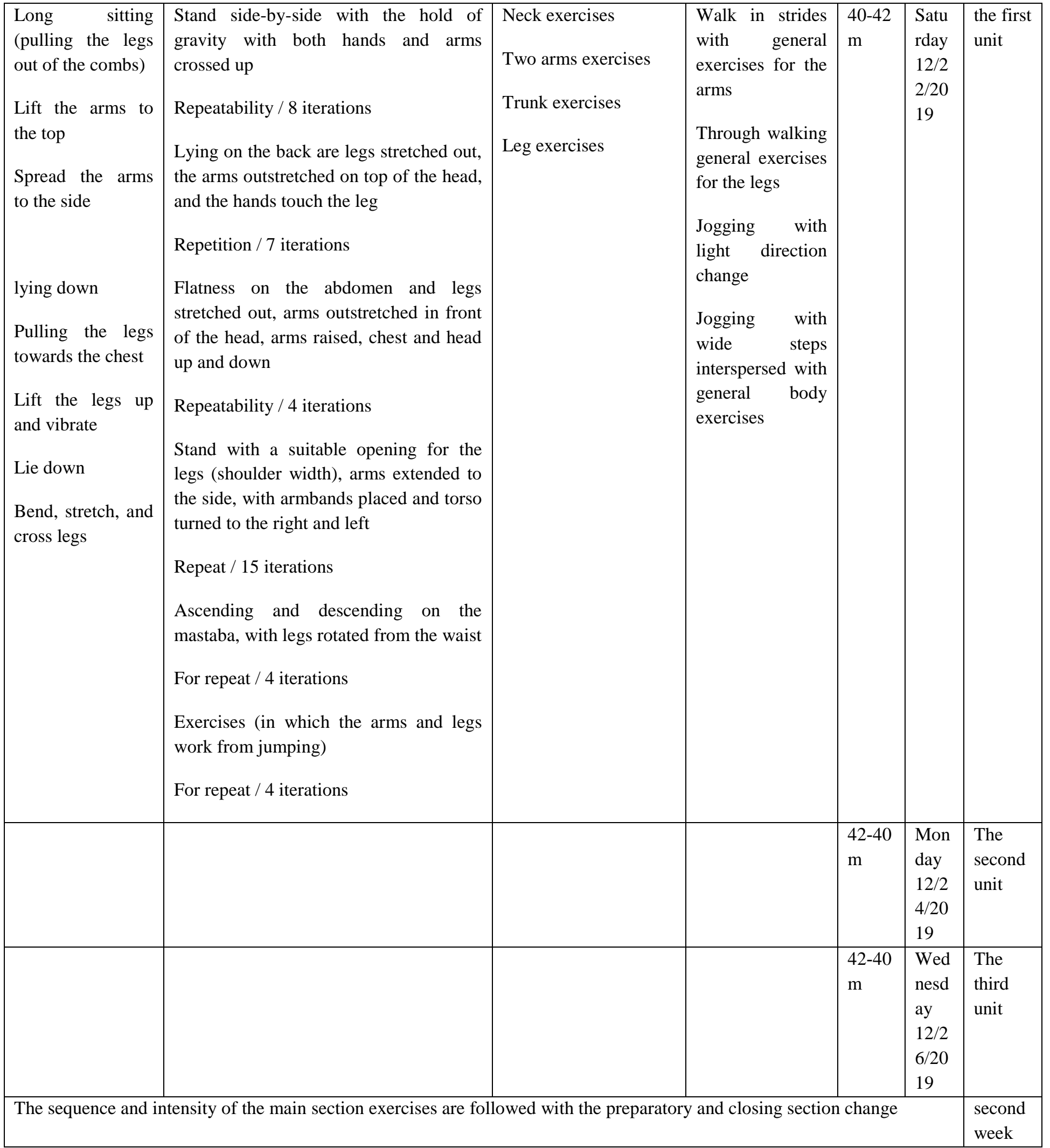

